\title{
Wireless Power Transmission Approach for Electricity Leakages Minimization in the Nigeria Power Grid
}

\author{
Femi-Jemilohun Oladunni Juliet \\ Department of Electrical and Electronic Engineering \\ Ekiti State University, Ado Ekiti \\ Ekiti State, Nigeria
}

\begin{abstract}
The bulk of electric power loss in Nigeria has been traced to the transmission segment of the national grid. While out of 180 million people in the country, only about $40 \%$ of this have access to a constant interrupted supply of Electricity, majority of the citizens in the remote areas are cut off from the national grid. A lot of technical challenges are confronting this network system of the power chain. The geographical terrain profile of the nation consisting of waters, hills, swamps over which the transmission cables run, impact negatively on the effectiveness and efficiency of the network. Also human influences on the transmission lines such as vandalism, theft, natural phenomenon and environmental disturbances culminated to the poor performance of this system. Many proposals had been suggested by researchers on the way forward to improve the generation and safe delivery of the generated power to the consumers while fortune had been invested by the Federal Government for the same purpose. Research is and must be on going until we realize the nation of our dream. This work proposes a wireless power transmission for the Nigeria Power sector as a way out of its erratic and inadequate supply of Electricity to the entire nation. It is believed that if this technology is pursued and implemented in the power sector, the whole nation will be lighten up in a short period of time and there shall be improvement in the revenue generation of this sector. While the economy of the nation will take an upward turn, and lives become comfortable for her citizen.
\end{abstract}

Keywords- Transmission, National Grid, Electricity, Wireless, power sector.

\section{INTRODUCTION}

Nigeria is located on the west coast of Africa and is the most populous country in the continent with a population of about 180 million. Among this numerous number, only $40 \%$ of them are connected to the national grid for access of electricity supply, even this small portion of the population connected faces erratic and acute shortage of the electric power supply, though there is campaign on generation shortage, yet the bulk of the generated power is not getting to the consumers due to inadequate and viable transmission network system [1]

Nigeria is divided into six geopolitical zones, sub divided into 36 states and the Federal Capital Territory. Nigeria has a vast landscape totaled to 923,768 sq. $\mathrm{km}$, out of which $98.9 \%$ is land. There is a varied layout of the country from flat open savannah in the North and thick rain forest in the south, with a myriad of scattered rivers, lakes and mountains. The features and physical terrain of the Nation pose great challenges to the adequate provision of power supply to every part of the country [2]. The Nigeria power transmission lines are found to stretch across several kilometers over wide waters and swamp as well as thick forests to cover the huge population of the nation scattered all over the vast land space of the nation. These elements along the path of the transmission lines constitute danger and hazardous situation which will prevent a seamless transmission of the electric power energy to the end users [3]. Power transmission involves the process of transporting the bulk of generated electricity from the generating station to the distribution station on the $330 \mathrm{kV}$ EHV grid and substation transmission lines of 132 and $33 \mathrm{KV}$ lines at $50 \mathrm{~Hz}$ [4]. Table 1 shows the statistics of electric power distribution to households in the six geological zones of the Country.

\section{A. Nigeria Electricty Power Sources and their Generation Capacities}

Electricity is generated through various sources such as water, Biomass, solar and thermal. There is no direct connection between the pool of generated electricity and the end users, rather it is stored in a reservoir and then transported to the consumers through the transmission network and distribution network of the power sector. The entire process from generation till it gets to the consumer is referred to as grid system. The technology that affords the generation of electricity power for instant use is called the off-grid network system. This technology is applicable in small community consumptions, it involves the individual managing the grid, and this form of electricity supply is capital intensive to sustain its effectiveness and efficiency. It requires the ability of the owner acquire enough capacity needed and regular maintenance of the facilities is important [5]

More than half of the nation population are cut off from the supply of electricity, those connected are faced with incessant power interruptions from time to time, there is a systemic challenge confronting all the aspect of power value chain of the country. This is encouraging the citizen against their interest and financial strength to invest in selfgenerated power through off-grid system [6]. The capacities of the various power generation sources are given in table 2 according to [5]. It is a sure fact 
considering the detail of the table that the Nation energy sources and production if well harnessed and exploited will serve its population better.

\section{B. Nigeria Power Sector Status}

There are three main sections of electricity production and services of the Nation Power sector:

Generation: record shows that as at year 2015, Nigeria has $12,522 \mathrm{MW}$ of installed capacity but only $3,879 \mathrm{MW}$ of this is functional due to technical challenges such as poor maintenance, water and gas constraints. About $85 \%$ of the installed capacity that require gas as fuel is also constrained by inadequate and low production of gas, vandalism occurrences, economic disincentives and poor infrastructure.

Transmission: The Nigeria transmission system is underutilized, its capacity being higher than the operational generation capacity of the power sector 5,300MW and $3,879 \mathrm{MW}$ respectively. Yet there is recurrent system collapses and power outages. About $50 \%$ of the generated power is lost between the generating point and the consumers. This loss is incurred due to technical, commercial and collection constraints [6].

Distribution: this is the last leg of the power grid which delivers the generated power through the transmission lines to the end users of the electricity through the 33/1/0.415 distribution lines.

The generation, transmission and distribution of electric power in our nation are based on wired networks across the country. It was reported by [7] that between the power generation networks and end users, power loss of about 26$30 \%$ is incurred as a result of resistance on the transmission and distribution cables. Hence the efficiency of the power generation, transmission and distribution is between 70$74 \%$. The technology involve in the transportation of the huge quantity of electric power generated from the generation segment of the power value chain to substation centers and then to distribution centers is referred to as electricity transmission system. The distribution center does the final supply of the electric power to residential and commercial end users. Transmission lines are distinct from the distribution cable, the interconnection of transmission lines forms the transmission network of the power system, the combination of both the distribution and transmission networks is referred to as power grid [8]

The power grid consists of components such as power lines, circuit breakers, cables switches and transformers. There are $5000 \mathrm{~km}$ distance of the $330 \mathrm{kV}$ lines, $6000 \mathrm{~km}$ of $132 \mathrm{kV}$ lines. The $330 \mathrm{kV}$ inject power to 23 substations of $330 / 132 \mathrm{kV}$ given a combined capacity rating of 6000MVA at a utilization factor of $80 \%$. Also the $132 \mathrm{kV}$ lines inject power to the 91 susbstations of $132 / 33 \mathrm{kV}$ having a combined capacity rating of $7800 \mathrm{MVA}$ at a utilization factor of $75 \%$ [8]

\section{Nigeria Power Sector Performance Appraisal}

The wheel of progress and advancement of any society hinged on and facilitated by the efficiency and effectiveness of her power sector chain. The growth in the socio-economic life and development of any nation responds to the level of inputs from the power sector of such country. Every class of citizenry of any nation require of a necessity, a stable, adequate and regular supply of electricity for daily living. The erratic and weak performance of the Nigeria power chain has limited the developmental growth and advancement of the entire nation [9]. Since the transmitted power is lower than the power generated, the difference has been traced to power losses by the resistance of the transmission lines. This is not helpful as the demands for electricity supply rises every passing day due to steady expansion in the population and consequently, increase in acquisition of appliances and devices that need the service of electric power. A drastic steps is required to reduce or eliminate such losses. One of the sure way is the new emerging technology of the wireless power transmission which is the focus of this work.

For any country to be classified as developed, the electric power supply of such must stand out, otherwise any country with erratic and epileptic supply has its interest of national development as a mirage with indefinite postponement of socio-economic development. This challenge will impact negatively on the nation economy as the potential foreign investors will find their way out of the country for a better and conducive environment. Electricity as a matter urgency, is a tool for development in any nation. "According to the international Energy Agency report (2012), electric power transmission and distribution losses in Nigeria stood at $17.22 \%$ in 2010 , and the maximum figure between 1971 and 2010 occurred in year 1981 where the loss stood at 49.27\%" [10].

Though the short fall in supply and demand has been traced to the gross inefficiency in the power generation yet the lack of adequate and suitable transmission network infrastructures has widened the gap between the demand and supply of electric power. The existing networks are being subjected to overloading and stress beyond the prescribe stability and thermal limits. Apart from the erratic supply of electricity to the consumers connected to the grids due to powers losses, lack of stability at the power chain, about 15.3 million households are devoid of access to the main grid for electricity supply [10]. Table 3 shows the comparison of energy consumption per capital of some countries.

The rural dwellers are the worst hit of the dearth, erratic and frequent outages supply of electricity. The state-of-art technology such as WPTA can salvage this situation, if the power sector can adopt this system at all levels of their system networks. This will increase the revenue generation, and add aesthesis to their service because the ugly sight of cables dangling, wire burnt and poles damage will be prevented for the long range transmission. Likewise, the clumsy scenarios in the homes and offices as a result of wire connection for various appliances and devices will be eradicated if WPT is adopted for short range power deployment. 
Table-1: Households without Electricity in the Geopolitical Zones of Nigeria (\%) [17]

\begin{tabular}{|c|c|c|c|c|c|c|c|c|c|c|c|}
\hline North West & $\%$ & North Central & $\%$ & North East & $\%$ & South West & $\%$ & South East & $\%$ & South-South & $\%$ \\
\hline Jigawa & 56.5 & Benue & 72.0 & Adamawa & 71.4 & Ekiti & 15.2 & Abia & 33.3 & Akwa Ibom & 38.3 \\
\hline Kaduna & 42.4 & Kogi & 48.1 & Bauchi & 58.5 & Lagos & 0.3 & Anambra & 38.3 & Bayelsa & 36.9 \\
\hline Kano & 56.2 & Kwara & 38.5 & Borno & 77.3 & Ogun & 20.4 & Ebonyi & 68.1 & Cross River & 46.3 \\
\hline Katsina & 59.7 & Nassarawa & 70.6 & Gombe & 55.4 & Ondo & 41.9 & Enugu & 48.5 & Delta & 46.3 \\
\hline Kebbi & 54.4 & Niger & 56.6 & Taraba & 88.8 & Osun & 33.9 & Imo & 12.6 & Edo & 15.2 \\
\hline Sokoto & 69.5 & Plateau & 71.3 & Yobe & 78.0 & Oyo & 38.8 & & & Rivers & 21.7 \\
\hline Zamfara & 77.1 & & & & & & & & & & \\
\hline Average & 59.4 & Average & 59.5 & Average & 71.6 & Average & 25.1 & Average & 40.2 & Average & 34.1 \\
\hline
\end{tabular}

Table-2: Nigeria energy resources

\begin{tabular}{|l|l|l|}
\hline Power sources & Generation Capacity & Available Capacity \\
\hline Large hydropower & $11,500 \mathrm{MW}$ & Only 1972 MW exploited \\
\hline Small hydropower & $3,500 \mathrm{MW}$ & $64.2 \mathrm{MW}$ exploited \\
\hline Solar & $3.5 \mathrm{~kW} / \mathrm{m} /$ day $-7.0 \mathrm{~kW} / \mathrm{m} /$ day & Refer to solar radiation map \\
\hline Sunshine & $4-7.5 \mathrm{~h} /$ day & \\
\hline Wind & $2-4 \mathrm{~m} / \mathrm{s}$ at $10 \mathrm{~m}$ & $\begin{array}{l}\text { height mainland Electronic Wind } \\
\text { Information disk (WIS) available }\end{array}$ \\
\hline Biomass & Fuel wood & $\begin{array}{l}11 \text { million hectares of forest and } \\
\text { woodland }\end{array}$ \\
\hline
\end{tabular}

Table-3: Energy Consumption comparison in some Countries [18]

\begin{tabular}{|l|l|l|l|l|l|}
\hline Country & $\begin{array}{l}\text { Population } \\
\text { (Million) }\end{array}$ & $\begin{array}{l}\text { Installed } \\
\text { Generating } \\
\text { Capacity } \\
(\mathrm{GW})\end{array}$ & $\begin{array}{l}\text { Generating } \\
\text { Capacity } \\
\text { (GW) }\end{array}$ & $\begin{array}{l}\text { Energy } \\
\text { Consumption } \\
\text { (billion kwh) }\end{array}$ & $\begin{array}{l}\text { Energy } \\
\text { Consumption } \\
\text { Capita (kwh) }\end{array}$ \\
\hline USA & $321,368,864$ & 1,074 & 1,053 & 3,883 & 12,083 \\
\hline Germany & $80,854,408$ & 204 & 178 & 583 & 7,204 \\
\hline UK & $64,088,222$ & 95 & 76 & 304 & 4,740 \\
\hline South Africa & $53,675,563$ & 47 & 44 & 234 & 4,363 \\
\hline China & $1,367,485,388$ & 1,646 & 1,505 & 5,523 & 4,039 \\
\hline Brazil & $204,259,812$ & 156 & 119 & 479 & 2,344 \\
\hline Egypt & $88,487,396$ & 39 & 27 & 129 & 1,462 \\
\hline Indonesia & $255,993,674$ & 53 & 41 & 156 & 609 \\
\hline India & $1,251,695,584$ & 309 & 223 & 758 & 605 \\
\hline Ghana & $26,327,649$ & 5 & 3 & 11 & 403 \\
\hline Nigeria & $172,562,056$ & 10 & 7.6 & 23 & 134 \\
\hline
\end{tabular}

\section{OVERVIEW}

The hinge on which the socio-economic and developmental growth of any nation Nigeria inclusive rotates is the quality and quality of its electricity supply to its citizenry. The realization of steady growth and industrial expansion as well as economy flourishing of any country requires accurate and consistent stable and uninterrupted electricity supply. Considering the state of power sector in Nigeria, the desire to be among the best countries in terms of viable economies may be a mere wish for a long time if drastic and adequate steps are not taken by all the stake holders to salvage the decay situation in this sector at the moment. It is no doubt that stable electricity will combat inflation, reduces costs of production, as the small business and large business owners have quality power supply to run their businesses making the country conducive for business expansion. This will in no small measure impact the lifestyles of the citizen in a positive dimension; job creation and gainful entrepreneurship will be undertaken by the people. Unlike the present situation in the power sector that had driven away the investors from the country due to huge amount of money they expend on fossil fuel to get their business running and on the long run, the end consumers bear the brunt of hick in prices of goods and services. Many attempts to provide and guarantee a stable and quality supply of electricity in the past and recent times had yielded little or no results. Huge funds and resources invested in the sector over the years had gone down the drain [8]

This paper aims at proposing a wireless power transmission approach to the rescue of the present challenge in the power sector. It is a sure and guarantee means to achieve quality, adequate quantity, stable and uninterrupted power supply for industries and residential uses. In achieving this, the transmission as well as distribution sections of the power chain are the focus of this paper.

\section{NIGERIA POWER SECTOR TRANSMISSION NETWORKS}

The history of Nigeria transmission networks dated to 1962 with the first $132 \mathrm{kv}$ link for power interconnection between Lagos and Ibadan. There was a progression in 1968 with emergence of the first national grid which birthed the construction of the Kainji hydro station with the capacity of $330 \mathrm{kV}$. There was a radial configuration of the transmission network in the three $132 \mathrm{kV}$ sub system for the Western, Northern and the Eastern parts of Nigeria. These two transmission systems were managed by two distinct bodies: Niger Dams Authority (NDA) and Electricity Corporation of 
Nigeria (ECN), while the $330 \mathrm{kV}$ transmission line was centrally controlled from Kainji power supply control room and $132 \mathrm{kV}$ network was managed by load dispatcher at Ijora power supply, Lagos. In 1972. The merger of these two bodies under the umbrella of NEPA took place in 1972, this is to facilitate a central regulation scheme of the sector [9].

According to [10], the coverage and capacity statistics of the Nigeria transmission network are as follows: $330 \mathrm{kV}$ with coverage of $5523.8 \mathrm{~km}$ while $132 \mathrm{kV}$ covers $6801.46 \mathrm{~km}$. There are $32330 / 132 \mathrm{KV}$ substations with total installed transformation capacity of 7688MVA, 105 132/33/11/KV substations with total installed transformation capacity of 9130MVA. The average available capacity on $330 / 132 \mathrm{kV}$ and $132 / 33 \mathrm{kV}$ are $7364 \mathrm{MVA}$ and $8448 \mathrm{MVA}$ respectively. The power transmission network system that links the power generation to the energy consumers through the distribution network is characterized with high power losses as the link travels long distances. This reduces the average power deliver to the end users, on the long run, insufficient power will be available for the consumers to operate the various appliances in the homes and offices. The transmission links are seldom constrained beyond its specified limit due to the demand of power supply to the end users, this may result in shortening the life operational expectancy of the system and total collapse if such situation persist. There are 159 substations under the Nigeria transmission network, this supposedly should increase the network capacity to $19,000 \mathrm{MW}$ with total coverage distance of the transmission lines of $15,022 \mathrm{Km}$. The transmission network capacity though higher than the operational generation capacity is still very low compared with the total installed capacity of the generation network of the power sector , 5300 to $12522 \mathrm{MW}$ respectively. A loss of about $7.4 \%$ is incurred along the transmission network, this is far more than the acceptable country benchmarks of about 2$6 \%$, this reveals the impacts of the inadequate infrastructure and technical challenges facing the network $[6,8]$. Some of the technical issues with the transmission network are lack of effectiveness and capability to safely deliver the generated electricity to meet the demand of the consumers and a numerous number unfinished transmission links projects. Other challenges are inadequate voltage profile in the northern part of the main grid, maximum capacity of the existing transmission lines $(4000 \mathrm{MW})$ at the moment, voltage frequency control and reinforcement and extension projects in the entire power sector [8].

It is also a fact that the coverage of the transmission network of the Nigeria power sector excludes some part of the nation. The network is susceptible to various disturbances being delicate and radial in nature. The transmission line cannot reliably match up with the generation network if the later begins to run at its full capacity [5]

Some of the technical challenges confronting the transmission networks according to [9] are itemized as follows:

i The limitation in the coverage distances which has deprived many rural dwellers access to the grid

ii The sector is poorly funded, the sole source of funding is from the government and it is grossly inadequate iii The total transmitting capacity is still far below the national energy demands even though the generation capacity is in the excess of what the transmission link can handle iv Some if not all the sections require total overhauling, the outdated equipment and redundancy in the sector does not promote effective service delivery to the consumers

v The regular maintenance, expansion and upgrading from time to time is lacking as the Government does not have resources to finance this.

vi The system is prone to incessant occurrence of vandalism of the electrical infrastructure due to lack of adequate security

vii The technologies used being obsolete are incapable of delivering correct voltage stabilities and profiles

viii There is lack of adequate working tools and machines for the technical crew to carry out the required operation on the network and routine maintenance as needs arise.

ix The entire Nigeria power sector lacks modern communication technology and monitoring gadgets

$\mathrm{x} \quad$ Some of the substations equipment are overloaded and stressed beyond their specified limit, hence total collapse is eminent with time

xi Lack of spare parts for immediate replacement in case of breakdown

xii Lack of routine human capacity building and recruitment of experts as at when due.

There is no doubt that the current main grid of the power sectors is incapable of handling the vast electricity being injected from the generation network and hence void of capacity to meet the expected future system delivery performance.

\section{A. Power Losses in Transmission lines of the National Grid}

The resistance of the conductors in opposition to the current flow is the major cause of power losses in the transmission and sub transmission network systems of the energy grid. The current flow generates heat which leads to temperature rise and consequently further increase the resistance of the cables and invariably, the power loss. Another losses worthy of consideration is the corona loss, the presence of corona on the transmission line results in power loss, this impacts on the efficiency of the transmission network system. These two type of losses are called ohmic and corona losses respectively and can be analysed mathematical according to [11] as follows:

$L_{\text {ohmic }}=R I^{2} \mathrm{kw} /$ phase

I denotes current along the conductor and

$\mathrm{R}$ represents resistance of the conductor.

$$
L_{\text {corona }}=242\left(\frac{f+25}{g}\right) \cdot \sqrt{\left(\frac{g}{d}\right) \cdot\left(V-V_{0}\right) \cdot 10^{-5}} \frac{\mathrm{hw}}{\mathrm{km}} / \mathrm{phase}
$$

where

f represents the frequency of transmission, 
$\delta$ denotes the air density factor, $\mathrm{r}$ is radius of the conductor, $\mathrm{d}$ represents the space between the transmission lines, Vis the operating voltage and

$V_{0}$ denotes the distruptive voltage. The total loss on the transmission line is the summation of the ohmic and corona losses as shown in (3)

$$
\begin{aligned}
& T_{\text {Loss }}=R I^{2}+242\left(\frac{f+25}{g}\right) \cdot \sqrt{\left(\frac{r}{d}\right) \cdot\left(V-V_{0}\right) \cdot 10^{-5}} \\
& \frac{\mathrm{hw}}{\mathrm{km}} / \text { phase }
\end{aligned}
$$

Generally,

$$
\begin{aligned}
& T_{\text {Loss }}=I^{2} \frac{\rho L}{A}+242\left(\frac{f+25}{g}\right) \cdot \sqrt[4]{\left(\frac{A}{\pi d^{2}}\right) \cdot\left(V-V_{0}\right) \cdot 10^{-5}} \frac{\mathrm{kw}}{\mathrm{km}} / \\
& \text { phase }
\end{aligned}
$$

where

$\rho$ is the resistivity of the conductor, $L$ denotes the length of the conductor and $A$ is the cross-sectional area of the conductor.

\section{B. Wireless Power Transmission Campaign}

Wireless power transfer is a new and emerging technology where electrical energy is transferred from generation point through the transmission links to the distribution point to loads and appliances through the air space without connection to cables and wires [12]. The emergence of this technology heralded by the advance and ubiquity in semiconductor technology is making a huge wave of transformation in the electrical engineering domain and can be adopted in the power sector globally [13].

In general, WPT systems entail transmission link to send and retrieve the signal with a free space as a medium between the links. Power can be transferred wireless over a short and long range. Example of short range transmission are : inductive coupling: uses electromagnetic induction for short range wireless power transmission ; another technique is the Resonant inductive coupling where power is transmitted by induction between coils at resonance and the third one is the Air Ionization: this involves wireless power transfer by the ionizing medium which is the free space [14]. The long range power transmission which is the interest of this work can be achieves through two major techniques: The Microwave and Laser Transmission. In the earlier, power is transmitted wirelessly to distance of kilometers using the power beaming with short wavelength in microwave range while the latter engages the conversion of electricity into a laser beam, this will be concentrated at photovoltaic cell for the wireless transmission of the energy [14]. Wireless power transmission being an effective and efficient way of electrical energy transmission can also be adopted for the distribution of electricity in places where the conventional way of wire drawing is difficult and not feasible [12].

\section{THE WAY FORWARD}

The challenging situation in the power sector has been so daunting and frustrating to the citizen as well as the government. It is an untold unpleasant story of the life without electricity for the numerous population of our dear nation. This in no small measure has impacted negatively on the economic and social development of the citizenry. There is a decline in the productivity of the nation power sector in the recent four decades. The economic and development of the nation that requires the services of power sector to thrive has experienced a dearth of such to its peril. The situation in the power sector has been acute power shortage and insufficient and poor quality of service. There is no doubt, considering the population of the country and steady increase every day, it is expected that social and economic activities will take a leap in the upward direction leading to increase in demand and consumption of electricity. It is unfortunate that the power sector is not bracing up to the task and expectation of the population, rather there is stagnation and downward turns sometimes in the performance of this sector. The current energy demand for the population is in the tune of 40,000MW. The power sector is still far from reaching and meeting this demand with their current meagre energy production of about 2900-4000MW [16].

The geographical structure of Nigeria is sparsely distributed especially the Northern part, this notwithstanding, electricity must be taken to all the citizen as part of their civil right regardless of their locations. Research shows that out of $45 \%$ of the Nigeria population with access to electricity, only $10 \%$ of this group belong to the rural dwellers. With the current population of Nigeria of about 180 million, more than $50 \%$ of this are rural dwellers, yet access to electricity is far from this group, no wonder, it is said that Nigeria though the most populous black country in the world, yet the poorest. It is not a gain saying that the development of any country is hinged on the access o to electricity, through which the natural resources can be transformed for economic boom of such nation. There is a mass shift from the rural settlement in the recent times to the city and this has imparted greatly on agriculture which happens to be the second resources for national revenue generation after the petroleum. Record shows that there is $25 \%$ reduction in the rural dwellers population between 1971 and 2009 as a result of migration to the cities [17].

The rural dwellers with great potential of feeding the entire nation has retorted to subsistent farming due to lack of social amenities and conducive environment that will ease the standard of living especially electricity which is needed to power many of the life made easy amenities.

The installation and maintenance of main grid to the rural areas can be capital intensive, options that are less stressful will be welcomed, especially situations where the national grid is cumbersome and the geographical terrain does not permit extension of the installation, hence making it uneconomical venture in such areas [5]. A report by [18] shows that in 2008 a total loss of $6.8 \%$ energy was incurred and this loss equals to $\$ 2.4 \mathrm{~B}$ worth of energy in Californians and a total sum loss of $\$ 24 \mathrm{~B}$ loss annually. This great loss is traced to the resistive and corona losses by the cables when energy in form of current is transmitted from generation to the consumers. There is dissipation of energy in form of heat in attempt by the current to overpower the ohmic opposition of the transmission wires [14]. The solution to this negative effects is to engage a system void of such losses with its non- 
resistance feature during transmission and WPT is the answer to this daunting challenge in the power sector.

\section{CONCLUSION}

The installation of electric power chain is very capital intensive, not withstanding, constant, stable and quality power supply cannot be negotiated. The prevalent situation in the country of paucity of fund demands that creative and innovative techniques are required to address the problems in the electric power sector. Adequate power generation, effective transmission of the generated power and safe distribution to the end user, will ensure the lifting of the country to be among the industrialized nations [19]

The daunting problem faced by the Nigeria power sector are due to recurrent collapse of the power grid as result of the heavy winds, water and vandalism of the network by the hoodlums, thieves and construction site workers. The overloading experience that characterized the nation grid equipment causes the tripping of such grid, loss of voltage and imminent collapse of the entire network. Protracted power outage is harmful to the productivity of both industry and individual and this brings a great deal of discomfort to all. Sustenance of stable power supply to the consumers all over the world is tasking and entails hard work and consistent dedication and faithfulness on the part of the stakeholders [8] The proliferation of wireless and ubiquity in telecommunication industry is affecting the lifestyle globally. This tremendous change has impacted virtually every field of profession and organization now, power sector cannot therefore afford to be left behind, It is time this sector goes wireless in their networks systems approach [7]. Nigeria can be lighten up by engaging Wireless Power transmission technology. The percentage energy losses can be avertedly engaged for useful application to the benefits of all.

\section{REFERENCES}

[1] Julia K.D,Nick H,Kyle M,Allison R "The Energy Crisis of Nigeria:An Overview and Implications for the Future" The University of Chicago 2008

[2] Sambo A.S "Matching Electricity Supply with Demand in Nigeria" International Association for Energy Economics, 2008

[3] Anthony .A. I "The Management Of Electricity Power Supply In Nigeria Problems And Prospects" Department Of Business Administration University Of Benin, Benin City, 2005.

[4] Sule, A. H "Major Factors Affecting Electricity Generation, Transmission And Distribution In Nigeria" International Journal of Engineering and Mathematical Intelligence, Vol. 1 Nos. 1 \& 3, 2010

[5] Elusakin J. E., Ajide O. O.and Diji J. C "Challenges of sustaining off-grid power generation in Nigeria rural communities" African Journal of Engineering Research Vol. 2(2), pp. 51-57, 2014.

[6] The Advisory Power Team, Office of the Vice President, Federal Government of Nigeria in conjunction with Power Africa. "Nigeria Power Baseline Report" 2015

[7] Mariya A .P, Gajendra A.N, Balaganesh R, .Manikandan R and Saravanan J "Wireless Power Transmission Using Inductive Coupling" International Journal of Emerging Technology in Computer Science \& Electronics (IJETCSE),Vol 8 Issue 1,2014.

[8] Kadiri K.O, Alimi M.O and Alabi A.O "Ways of Achieving Stable and Uninterrupted Power Supply of Electricity in Nigeria" British Journal of Applied Science \& Technology 10(5): 1-15, 2015

[9] Abanihi V.K, Ikheloa S.O and Okodede F "Overview of the Nigerian Power Sector" American Journal of Engineering Research (AJER) Volume-7, Issue-5, pp-253-263, 2018
[10] Ohajianya A.C, Abumere O.E, Owate I.O and Osarolube E "Erratic Power Supply In Nigeria: Causes And Solutions" International Journal of Engineering Science Invention Volume 3 Issue 71, PP.5155,2014

[11] M.O. OKE M.O and BAMIGBOLA O.M "Minimization of Losses on Electric Power Transmission Lines" Journal of Mathematical Theory and Modeling Vol.3, No.7, 2013

[12] Syed K.R, Omar A, Saiful I, Rafiul A, and Shariful I "Design and construction of wireless power transfer system using magnetic resonant coupling" American Journal of Electromagnetics and Applications . 2(2), 11-15 2014.

[13] Meghana K, Divya G, Udaykumar K and Kunal P "Wireless Power Transfer (Electricity Out Of Thin Air)" Project in Jain College Of Engineering Belgaum

[14] Mystica A.M.D "Wireless Power Transmission" International Journal of Scientific \& Engineering Research, Volume 5, Issue 10, 2014

[15] Wamalwa P W "Wireless Power Transmission" School of Engineering Department of Electrical University Of Nairobi, 2016.

[16] Onochie U.P, Obanor A, Aliu S.A "Electricity Crisis in Nigeria: The Way Forward" American Journal of Renewable and Sustainable Energy Vol. 1, No. 4, pp. 180-186, 2015.

[17] Chibuzo John Paul Igwemezie “A Critical Analysis Of Electricity Distribution Processes In Nigeria: A Management Perspective" EMS Faculty School of Government University of the Western Cape, 2016.

[18] Sunday O. O, Olufemi P. B, Stephen C. N, Oluwaseun K, Richard O. L, Abraham K. A, Tunde A, Joseph A. O, Abiodun O. A, Orobome L. A “ Towards a Sustainable Electricity Supply in Nigeria: The Role of Decentralized Renewable Energy System" European Journal of Sustainable Development Research, 2(4), 40, 2018

[19] Sambo A.S, Garba B, Zarma I.H and Gaji M.M "Electricity Generation and the Present Challenges in the Nigerian" Power Sector Energy Commission of Nigeria, Abuja-Nigeria, 2006 